1.3 per cent. of urea. Uader the microscope a few hyaline and granular casts were seen with renal and bladder epithelium. On July 9th the albumin measured 0.05 per cent. and the total quantity of urea passed in the 24 hours amounted to 140 grains. On August 6th, after centrifugalisation, no casts were discovered. The optic discs showed considerable blurring of the edges, obviously due to odema. In the right disc the veins were greatly enlarged and very tortuous; the arteries were also large. The outer part of the disc showed a very remarkable group of small arterioles and enlarged vessels were seen scattered about the retina. Near the macula was a small patch of pigment, which Dr. D. C. Lloyd Owen, who kindly examined the discs, informed me was the result of former choroiditis. The left disc showed similar appearances but to a much slighter degree. The blocd counts were as follows :-Red corpuscles: June 29th, 7,000,000; July 1st, 8.045,000; 19th, 7,900,C00; 22nd, 6812,000 ; August $5 \mathrm{th}, 7,518.750 ; 19 \mathrm{tb}, 6,297,000$; Sept. 8th, 8,650,000; and Oct. 2nd, 6825,000 . White corpuscles: June 29th, 7000 ; July 1st, 7000 ; and 22nd, 5600. The bromoglobin was estimated on July 22nd by Oliver's bæmoglobinometer and was much in excess of the limit of the scale, which registers up to 120 per cent. Three differential counts of the white corpuscles were made with the following results :-Polymorphonuclears: July 1st, 74 per cent.; 22nd, 61.4 per cent. ; and $29 \mathrm{th}, 70.5$ per cent. Lymphocytes: July 1st, $19 \cdot 3$ per cent.; 22nd, $29 \cdot 4$ per cent.; and 29th, 20.0 per cent. Large mononuclears and transitionals: July 1st, $6 \cdot 3$ per cent.; 22nd, $7 \cdot 3$ per cent. ; and 29th, $7 \cdot 9$ per cent. Eosinophiles : July 1st, 0.2 per cent.; 22nd, 1.9 per cent ; and 29 th, 1.6 per cent. No abnormality in the size or shape of the red corpuscles was observed during any of the differential counts and no nucleated red cells were seen. On one occasion two myelocytes were noted in a prolonged count. No estimation was made of the viscosity of the blood but Mr. J. Priestley Smith on three occasions examined the blocd with regard to its coagulability by a method which he has not yet published. He gives me the following note: "The method employed aims at measuring, not the time necessary for coagulation, as in Dr. Wright's method, but the force required to break the clot when it is fully formed. The blood is of measured quantity, is placed between two surfaces of ground glass, the one plane, the other of known curvature, and is protected from evaporation. In the case here described the breaking force was greater than that of normal blood. It was, however, much less than that which I have found in leucocythrmia. The method is as yet, I think, too new to justify publication of details." With rest in bed the cardiac symptoms improred. Within a few days the odema disappeared and it did not return on getting up. The cardiac enlargement slowly diminished and by the beginning of August the impnlse was within the nipple line, though the upper limit of dulness still extended into the second space and the pulsation and diastolic shock remained noticeable in the pulmonary area. A faint apical systolic murmur was still to be heard on the patient's discharge from the hospital. As shown by the above blood counts the polycytbrmia diminished with the improvement in the condition of the heart but it did not disappear. The count of 8,650000 on Sept. 8th was the first made after the patient's transference to the Jaffray Hospital, which is situated some three and a half miles from the General Hospital. The journey was made in an ambulance and involved no fatigue and the patient had been walking about the ward for some time before her removal. I doubt, therefore, whether the high count can be attributed to the effects of the journey. This and the last count were not made by myself. With the marked improvement in the cardiac physical signs there was no recognisable change in the cyanosis or in the engorgement of the conjunctival and retinal vessels.

In endeavouring to arrive at a conclusion as to the nature of the polycythæmia there is much to be said in favour of regarding it as merely an accompaniment of the cyanosis due to weakness of the cardiac muscle. Although in the hitherto published cases of splenomegalic polycytbæmia slight enlargement of the heart has occasionally been noted and in several cases there has been a soft apical systolic murmur, yet, with one exception, none of them has shown any definite symptoms of cardiac incompetence. The one exception is to be found amongst the seven cases published by Türk, ${ }^{1}$ but as there was here advanced chronic nephritis with symptoms of heart failure I should be inclined to doubt the advisability of including the case in the above-named group. The age of my patient is perhaps a little against the diagnosis of splenomegalic polycythæmia, only two of the recorded cases so far having occurred in patients under 30 years of age and 24 being the age of the youngest. The magnitude of the polycyth mia is no reason for denying it a cardiac origin, for Dr. G. A. Gibson ${ }^{2}$ has recorded one case of mediastino-pericarditis with a red cell count varying from $8,000,000$ to $8,800,000$, and one case of chronic bronchitis and emphysema with mitral incompetence, and another of pure mitral incompetence, in each of which the red cells numbered $7,500,000$ to the cubic millimetre. It is to be noted, however. that in the first two of these three cases the polycytbæmia completely disappeared with the cessation of the cardiac symptoms; the result of treatment is not noted in the third case. In my case, although the signs and symptoms of cardiac incompetence nearly disappeared, the polycythæmia still persisted at the time of the patient's discharge from the hospital though in a lesser degree than on admission, and the remarkable appearance underwent no alteration. In addition to the persistence of the polycytbæmia the curious dilatation of the conjunctival and retinal vessels and the pigmentation of the trunk are in favour of the alternative diagnosis. The differential white cell count is, on the whole, in accordance with that found in most of the splenomegalic cases, though the percentage of polymorphonuclear Jeucocytes is not quite so high as that generally noted. No normoblasts were seen at any time, whereas in many, but not all, of the splenomegalic cases a few of these cells have been observed. Much wejght can hardly be attached to the presence of the two myelocytes seen on one occasion but, as far as it goes, this fact tends to connect the case with the splenomegalic group. As already stated, there was no marked enlargement of the spleen in my case but a similar absence of enlargement has been noted in two of the published cases of splenomegalic polycythæmia.

I have assumed in this discussion that the latter condition is a "definite clinical entity," to use the words of the Editors of THE LANCET in a note preceding my paper published in that journal on Feb. 22nd, 1902. This assumption is disputed by Dr. Gibson, who is inclined to regard the condition as merely one secondary to cardiac weakness. But the case under Dr. R. Saundby's care published in that paper was ko entirely free from symptoms of heart weakness and the clinical picture was so totally unlike that of any cardiac case that $I$ have seen that I cannot feel any doubt that it must bave another pathology. At present Dr. F. Parkes Weber's explanation of the condition as due to an "increased erythroblastic activity involving a great part, but not necessarily the whole, of the bone marrow," seems likely to hold good. At all events, no other satisfactory theory bas been proposed.

Birmingham.

\section{A CASE OF HEMATOMYELIA DUE TO TRAUMA,}

WITH OBSERVATIONS ON THE COURSE IN THE SPINAL CORD

OF THE SECRETORY NERVES TO THE SWEAT GLANDS.

BY W. A. REES, M.B. LoND., F R C S. ENG., Registrar aND Pathologist at THE BOLINGBROKE hosPital.

НжмАтоMYELIA is the term used for hæmorrhage into the grey matter of the spinal cord. The hæmorrhage is due to trauma in 90 per cent. of the cases and is caused by fracture or dislocation of the vertebræ in some cases ; in others the injury may give rise to hæmorrhage in the grey matter without any actual lesion to the bony canal. In all of Thorburn's cases the hæmorrhage occurred at the level of the fourth, fifth, and sixth cervical vertebræ, and he considers it probable that the hæmorrhage is usually produced by a partial dislocation with recoil. The hæmorrhage takes the form of a cone, or rather of two cones, tapering off upwards and downwards and extending over a considerable length of grey matter. This spread of the bæmorrbage

2 Abstract of a paper read before the Royal Society of Edinburgh, 2 Abstract, of a paper read before
THE LANCET, Jan. 17th, 1903, p. 155. 
through the grey matter around the central canal is due to the blood tracking along the line of least resistance, for experiments in animals have shown that fluids injected into the spinal cord tend to find their way into the grey matter and spread through it in preference to the white matter. Hæmatomyelia is not so very uncommon-five cases were admitted into the Manchester Royal Infirmary in three years-and the condition is liable to be mistaken for one of simple crush of the cord unless the symptoms are carefully investigated. The hæmorrhage in the following case probably started at the first dorsal segment of the cord, producing its maximum effects at this level, but it also spread upwards to the fourth cervical and downwards to the third dorsal spinal segments.

The patient, a brewer's drayman, aged 42 years, was admitted into the Bolingbroke Hospital on Angust 30th, 1905, under the care of $\mathrm{Mr}, \mathrm{H}$. Burrows. He was being driven along in his dray when he slipped and fell out over the back of the cart. He turned a "somersanlt" as he fell and struck the back of his head and shoulders on the ground, the head being forcibly bent forwards on to the chest at the same time. He felt something go "click" at the back of his neck but was not stunned at all by the fall and was immediately helped on to his feet. He was quite positive that he was able to use his legs and even to stand with support immediately after the accident but within a few minutes he felt a numbness spreading downwards from the trunk to the lower limbs and in about five minutes the legs were completely paralysed. He was admitted into the hospital about half an hour after the accident

On admission the patient was a healthy-looking man, very tall and strongly built; he was quite sober and could give a clear account of the accident. There was a small abrasion on the back of the head but no deformity or irregularity about the spine. The third dorsal vertebra was tender on firm pressure. The pupils were equal and reacted to accommodation and light. Both arms were weak and as he lay in bed he could only just manage to raise his hands to his mouth. The lower six intercostal muscles, the abdominal muscles, and the muscles of the lower limbs were completely paralysed, respiration being carried on by the diaphragm only. Sensation was unimpaired in the head, the neck, and the arms except for the skin over the little and ring fingers of each hand where there was considerable numbness. On the front of the chest sensation was normal above the level of the nipples, while below this level the sense of pain and temperature was absent. The upper limit of this "dissociation of sensation" was variable: thus on tracing out the area for anæsthesia to pain with a prick of a pin from above downwards the prick could be perceived as a painful sensation as low as the level of the fifth rib in the nipple line, while in the reverse direction the prick did not cause any pain till the level of the third rib was reached. The lower limit for perception of temperature varied equally and was at a slightly higher level on the chest wall than that for the sense of pain. On the back sensation was normal at the level of the first dorsal vertebra; from here to the sixth dorsal vertebra the sense of pain was present but was bluntea (thus the patient could not distinguish between a prick and a pinch); from the sixth dorsal vertebra down. wards there was no perception of pain or temperature. All over both legs the dissociation of sensation was well marked, the very lightest touch being distinctly felt. The kneejerks were present on admission but disappeared completely by the third day to reappear again at the end of the first week, and by the tenth day from the accident they were markedly exaguerated. Priapi $m$ and turgidity of the penis were noted. The urine was retained and the motions were pa sed involuntarily

By the fifth day after admission voluntary power in the arms had returned completely. At first the patient complain $d$ of a severe gnawing pain in both elhows in the neighbourhood of the internal conilyle. There was no local lesion here and the pain seemed to be a referred pain along the ulnar nerves from the spine. A good deal of pain in the back of the neck was experienced also. A catheter was passed twice daily for five weeks, by which time, owing to the return of $p$ iwer in the abdominal muscles, he was able to empty hi : bladder naturally. The occurrence of cystitis $w_{1} /$ preventied by careful cleansing of the penis e ch time the cttheter was $u$-ed and by wrapping the oryan $i$ an antiseptic dre-sing in the intervals; in addition urutro in was yiven from the beginning as a prophylactic. Atrer six weeks there was slight return of voluntary power in the legs, but by this ime the legs were becoming very spastic and splints had to be used to correct the tendency to flexion and adduction. During the first week there was a passive serous effusion into both knee-joints which showed a tendency to recur later; this may have been a trophic change comparable to the joint affections of syringomyelia, At the end of two month there was marked atrophy of the muscles of the thenar and hy pothenar eminences and the interossei of both hands.

The man was discharged from the hospital on Nov. 24th. $\mathrm{He}$ was readmitted on Feb. 9 th, 1906, because the flexion deformity of the legs had greatly increased; painful spasms preventing sleep octurred in the legs at frequent interval and the knees could not now be straightened beyond a right angle and had become so pressed together by the spasms of adduction that a large sore had formed over the inner condyle of the right leg. There were several sores on the posterior surfaces of the legs, caused by the splints which had been employed ineffectually to correct the deformity. Under chloroform the inner and outer groups of hamstring muscles were tenotomised and the legs were forcibly straightened and fixed on a Thomas's double extension and abduction frame, the abduction being about four feet at the level of the ankles. Owing to the overstretching the adductor muscles became quite powerles and the adductor spasms ceased at once, and the flexion spasms were rendered very slight and occasional the patient experienced great relief from the first and was able to sleep again. He was kept on the frame for a fortnight and then it bad to be omitted owing to the formation of pressure sores; the knees now could be kept straight by means of short back splints and the power in the legs was much improved; the right leg could be raised off the bed and abducted and adducted at will so long as the knee was kept straight by a back splint. This method of overcorrecting deformities produced by paralysis is especially useful in spastic paralytic conditions, as in addition to preventing the occurrence of the spasms it allows the weakened opposing muscles to regain their tonicity and power and the general effect on the strength of the $\operatorname{limb}$ is most marked. The great difficulty in these spinal cases is the formation of pressure sores and with every care these are nearly bound to occur; still the benefits derived from the use of the frame quite outweigh this disadvantage.

Remarks. - The presence of the reflexes on admission is interesting; it may perhaps be explained by the fact that the hæmorrhage had not finished extending as the case was seen so soon after the accident; later by the third day the hæmorrbage had produced its maximum effect and the reflexes were consequently entirely abolished. At the end of the first week the reflexes reappeared and became exaggerated, as is usually the case when the lesion is well above the lumbar enlargement.

No spinal myosis was observed in this case; it may have been overlonked, as Thorburn considers this symptom nearly a sine quấ non in hæ natomyelia ; on the other hand, Gowers in an account of the affection in his "Diseases of the Nervous System" does not even mention this symptom.

The dissociation of sensation was present and well marked and continues at the present time, seven months after the accident, though it is not now so definite as at first. The level of the arrasthesia on the front of the chest pointed to the lesion not reaching the fourth cervical segment of the cord, for the descending branches from the third and fourth cervical nerves to the skin of the upper two or three intercostal spaces were unaffected. The fact that sensation behind extended very much lower than segmental appearances would lear one to expect is difficult to explain but is almost universally met with (Thorburn).

Bedsores proved a most troublesome complication; the heel could not be left in contact with the bedclothes unprotected by wool for an hour withont blistering, and if the patient was rolled over on to his side a sore would form over the great trochanter in a very short time in spite of water beds and other precautions We see, therefore, that it is not the posterior columns of the cord which convey the trophic nerves to the skin. for these were undamaged in this patient, but it is the grey matter which controls the nutrition of the skin.

The diarnosis of bæmatomyelia rests on the suddenness of the onset of the symptoms after the accident; in this case it was only a matter of minutes, in Dr. S. J. Sharkey's casel it was three hours and this would probably be the outside liwit. There are no initial spasms and rigidity as in spinal 
meningeal hæmorrhage, which also takes longer to develop. No initial fever is present as in myelitis, a point which is of great importance in diagnosing between the non-traumatic cases of hæmatomyelia and myelitis. The dissociation of sensation is most characteristic and distinctive of the disease. The atrophy of groups of muscles, in this case of the small muscles of the hands, points to a central destructive lesion in the grey matter of the anterior cornua. The site of the lesion also-namely, in the lower cervical region-is characteristic.

The prognosis is better than could be expected from the initial severity of the symptoms; if the patient gets over the immediate dangers of bronchitis, cystitis, secondary myelitis, and bedsores he gradually recovers some power in the legs and the process of improvement extends over a period of a year or more.

Observations on the course of the secretory fibres to the sweat glands.-The following observations with regard to sweating were made on this patient at the end of the first week atter the accident. An injection of pilocarpine nitrate (one-fifth of a grain) was given subrutaneously and was followed by a furtber injection of one-sixth of a grain in half an hour. Sweating was produced all over the body but was most marked on the lower limbs and trunk below the level of the nipples. On the next day the patient was given a hot-air bath in the ordinary way, the hot air entering from the foot of the bed and passing over the legs and then over the rest of the body. Atter 20 minutes sweating occurred which was distributed over the body as follows. The head, which was necessarily not included in the bath, neck, arms, and upper half of the chest sweated profusely; the lower half of the chest and upper part of the abdomen were only just moist ; while the rest of the body below the level of the iliac crests was quite dry. At the same time there was a rise in body temperature of two and a half degrees.

These simple observations, I think, raise the following points in regard to the nervous mechanism of sweating in the human subject. They were carried out at the end of a week after the injury, as by then the vessels supplging the paralysed parts ought to have recovered their tone and the initial vasc-dilatation should have subsided. In the first observation the increased sweating in the paralssed parts is due to the uncontrolled action of the pilocarpine on the cells of the sweat glands in these parts. This effect has been used by Victor Horsley and others to determine exactly the upper limit of a spinal lesion, especially before an operation is performed for the relief of pressure by laminectsmy; it is also useful as a means of distinguishing functional paraplegia with anæsthesia from organic disease. The object is much better attained by means of the second method, which allows comparison to be made between the absolute dryness of the skin in the paralysed parts with the profuse sweating present in the unaffected region.

In animals there is a subsidiary sweat centre in the lumbar enlargement of the spinal cord, for if in the cat the spinal cord be cut across above the exit of the twelfth tho acic nerves and the animal exposed to hot air $\left(60^{\circ}\right.$ to $70^{\circ} \mathrm{C}$.) for from five to ten minutes sweating still occurs in the hind limbs (Luchsirger). On the other hand, in man there is no positive evidence of the existence of such a centre in the lumbar cord; in the cases of injury to the cord where the sweating has been recorded there has always been an interference with reflox sweating, as in this case. The lumbar sweat centre may, however, have had its excitability so depressed by the injury that no reflex sweating could occur in animals the experiment does sometimes fail, probably from this cause. The mere fact that reflex sweating does occur in animals is positive evidence for the presence of a sweat centre in the lumbar cord in animals, while the fact that reflex sweating has not been observed in man is negative evidence as far as it goes against the preseoce of a sweat centre in the lumbar cord in man. The ab lition of the reflexes at first after a spinal injury $p$ ints to the general depression in the excitability of the cord but in this instance the experiment was carried out at the end of the first week at a time when the reflexes were returnirg and becoming exaggerated and therefore the spinal sweat centre, if it had existed, should no longer have had its excitabilito lowered by the accident. We want, however, further clinical evinence on this point, as tile cases where any record of the sweating below a spinal lesion has been kept are too few to allow one to dogmati en the point. If it is granted that the lumbar sweat centre is non-oxistent in man, th en normally sweating is proruced by impulses con. veyed to the periphery by secretory nerve fibres which pass down the cord from the sweat centre or centres situated in the medulla or upper part of the cord ; the passage of these impulses was interrupted in this patient by the hæmorrhage in the cervical region into the grey matter round the central canal. This fact affords, therefore, some evidence that the secretory fibres for the sweat glands pass down the spinal cord in the grey matter. The rise of two and a half degrees Fahrenheit in the body temperature showed how the heatregulating apparatus is put out of working order in these cases of spinal injury.

I am indebted to Mr. Burrows, under whose care the patient was while in the Bolingbroke Hospital, for leave to publish these notes.

Bolingbroke Hospital, S.W.

\section{MOTOR-DRIVER'S SPINE (?).}

BY W. J. BURROUGHS, M.R.C.S. ENG., L.R.C.P. LOND.

THAт the list of diseases depending for their causation upon the occupation of their victim is already a lengthy one few will question. Doubtless, also, as such occupations increase so in like manner will the diseases arising therefrom. The case the details of which I subjoin is probably yet another addition to the already considerable total and may possibly prove of some degree of interest when viewed in that light.

The facts are as follows. On the morning of April 4th last I was called to a strong, healthy-looking man, of fine physique, who informed me that his work was that of a motor omnibus driver. His age, he stated, was 34 years, his height was six feet, and his weight was 14 stones. His father, previously a healthy man died at the age of 59 years from some acute form of diarrbœa which was neglected. His mother, aged 70 years, bad always been, and still is, a healtby woman. He had, too, be said, one sister, aged 29 years, who had always enjoyed excellent health, as she does at the present time, and two brothers who died in early infancy, the cause of their decease in either instance being unknown to him. Personally, the patient said that he had always been a very healthy and temperate man, a fact borne out by his personal appearance. He had never suffered from any venereal disorder, neither was there any history of external injury to account for his present condition.

On the day previous to his illness (April 3rd) he began his work at 3 P.M. and continued to 12 midnight. The engine he drove was a 30 horse-power Mercedes. I merely mention this fact as an engine of such horse-power requires a very considerable amount of physical energy to start it and in an ordinary way it is set in motion in the morning and does not require restarting all day but is simply connected or disconnected as movement or the reverse is required of the vehicle. On this particular day, however, a certain portion of the mechanism acte $d$ badly and cansed the engine to stop a considerable number of times and on each occasion it had to be restarted by the patif nt. Whether on this account or on that of the extra vibrat on produced by the defective working of the machinery, he appeared to have felt more than usually exhausted on his return home and on the following day his condition was as follows. His facial expression was one of anxiety and be was obviously in a highly nervous state, getting easily excited. He complained of persistent acute pain which he referred to the right hip and which became so intensified by pressure that he was unable to lie on that side. He also noticed a dull aching pain across the loirs, more pronounced on the right and, further, that he was unable to move the leg of this side, which he described as being so painful that he could scarcely bear the weight of the bedclothes upon it. Owing to the tenderness of the right hip and back he found the po-ition of the greatest ease either in resting upon his left side or in an attitude of semi-pronation.

On examination his pulse was 75 , his respirations were 20 , and his temperature was $986^{\circ} \mathrm{F}$. (no temperature higher than this was recorded throughout). His pupils were equal and reacted to light and there was no loss of accommodation. Tenderness on pressure was experienced to the right of the third and fourth lumbar spines. extending outwards for about six inches over an area about three inches wide. The whole of the right leg was in a state of spastic rigidity. Both 